\title{
A gestante no pré-parto: a fisioterapia traz benefícios?
}

A gestação tem sido, geralmente, um acontecimento que proporciona grande felicidade para a grávida e para a família. O parto é um evento rodeado de emoções e sensações, em especial para a mulher e para o bebê, que são as figuras principais. Este artigo busca proporcionar conhecimento quanto à atuação do fisioterapeuta durante o período do pré-parto, apontando os principais benefícios dessa presença nesse período que é extremamente importante para mãe, filho e família. No âmbito do atendimento hospitalar a fisioterapia atua utilizando, principalmente, cinesioterapia, banhos quentes, massagens terapêuticas, técnicas respiratórias, caminhada, posturas verticais, exercícios com a bola suiça e neuroeletroestimulação transcutânea (TENS). Esses recursos buscam proporcionar ao paciente alívio da dor e conforto durante o trabalho de parto. Foi realizada uma pesquisa documental através de busca online em bases SCIELO, Portal de Periódicos da CAPS, LILACS, BIREME e livros do acervo da biblioteca da Faculdade Guaraí, totalizando uma análise de 21 documentos. Ao finalizar a pesquisa, verificou-se que o fisioterapeuta é um profissional extremamente importante no atendimento à gestante no pré-parto, trabalho de parto e pós-parto. Através de um acompanhamento especializado à gestante conquista-se uma assistência de qualidade aumentando o bem-estar para mãe e bebê no período gestacional e em todo o processo de parto.

Palavras-chave: Assistência Hospitalar; Gravidez; Trabalho de Parto.

\section{A pregnant woman in pre-partum: does physiotherapy bring benefits?}

Gestation has generally been an event that provides great happiness for the pregnant woman and the family. Childbirth is an event surrounded by emotions and sensations, especially for the woman and the baby, who are the main figures. This article aims to provide knowledge about the physiotherapist's performance during the prepartum period, pointing out the main benefits of this presence in this period that is extremely important for mother, child and family. In the scope of hospital care, physiotherapy mainly uses kinesiotherapy, hot baths, therapeutic massages, respiratory techniques, walking, vertical postures, Swiss ball exercises and transcutaneous neuroelectrostimulation (TENS). These features seek to provide the patient with pain relief and comfort during labor. A documentary search was conducted through online search on SCIELO databases, Portal of Periodicals of CAPS, LILACS, BIREME and books from the collection of the Faculty of Guarai, totaling an analysis of 21 documents. At the end of the research, it was verified that the physiotherapist is an extremely important professional in the care of the pregnant woman in the prepartum, labor and postpartum. Through a specialized accompaniment to the pregnant woman, a quality assistance is achieved, increasing well-being for the mother and baby in the gestational period and throughout the process of childbirth.

Keywords: Hospital Assistance; Pregnancy; Labor of Delivery.

Topic: Fisioterapia

Reviewed anonymously in the process of blind peer
Received: $18 / 08 / 2019$

Approved: 25/08/2019

Simone Ribeiro de Souza

Faculdade Guaraí, Brasil

http://lattes.cnpq.br/0912403004106406

iagoeian0809@gmail.com

Izís Moara Morais Leão

Faculdade Guaraí, Brasil

fisio.izismorais@gmail.com

Leandro Augusto Almeida

Faculdade Guaraí, Brasil

http://lattes.cnpq.br/2633523421162158

leandroaugustoalmeida74@gmail.com

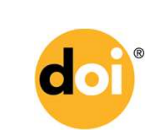

DOI: 10.6008/CBPC2236-9600.2018.002.0011

\section{Referencing this:}

SOUZA, S. R.; LEÃO, I. M. M.; ALMEIDA, L. A.. A gestante no pré-parto: a fisioterapia traz benefícios?. Scire Salutis, v.8, n.2, p.104-114, 2018. DOI: http://doi.org/10.6008/CBPC2236-9600.2018.002.0011 


\section{INTRODUÇÃO}

O período gestacional é considerado um processo fisiológico no qual ocorrem inúmeras mudanças estruturais e funcionais no corpo da mulher, tais como, alterações mamárias, endócrinas, cardiovasculares, neurológicas, gastrointestinais, metabólicas, respiratórias, dermatológicas e ganho ponderal. A gestação é dividida em três trimestres, cada um tendo suas mudanças específicas. No decorrer dessas etapas, é comum a queixa de dores nas costas, incômodos posturais e respiratórios e variações de humor havendo consequentemente um quadro de ansiedade.

O trabalho de parto se inicia geralmente de três formas: ruptura da bolsa amniótica, sangramento e contrações que se intensificam. Porém, ocorrem episódios de falso trabalho de parto que imitam o verdadeiro, no entanto essas contrações, apesar de intensas, podem cessar diante de uma mudança de atividade como caminhar ou ficar em repouso. Todavia, quando ocorre o verdadeiro trabalho de parto, as contrações não desaparecem, tornando-se cada vez mais intensas e ocorrendo em um período de tempo menor. Em média o trabalho de parto tem duração de 12 a 14 horas para a primeira gestação e 6 a 8 horas para as gestações seguintes.

A evolução do trabalho de parto pode ser dividida em quatro etapas: compreende o período de dilatação cervical, de expulsão fetal, de dequitação ou expulsão placentária e período de Greenberg. 0 primeiro período se caracteriza pelo início das contrações e pela dilatação do colo uterino que ocorre em velocidade média de $1 \mathrm{~cm} / \mathrm{h}$ em primíparas e sendo mais rápido em multíparas. O período expulsivo inicia com a dilatação completa e a passagem do bebê pelo canal de parto, com duração aproximada de 1 hora nas primíparas e de 40 a 45 minutos nas multíparas. Após 5 a 10 minutos da expulsão fetal a placenta é eliminada. O período de Greenberg ocorre após 1 hora da dequitação da placenta, onde se volta um cuidado maior para a ocorrência de quadros hemorrágicos que são frequentes.

Os programas multidisciplinares que atuam no preparo para o parto vêm sendo desenvolvidos com o intuito de possibilitar na parturiente o equilíbrio físico, psíquico e a sensação de bem-estar. Esses programas viabilizam benefícios, como a diminuição dos sintomas de desconforto e dor do parto, controle da ansiedade, diminuição do tempo de trabalho de parto e menor índice de indicação para parto cesárea.

O fisioterapeuta está inserido na equipe multidisciplinar, desempenhando o trabalho de avaliação e monitorização das alterações físicas da gestante, focalizando a segurança da parturiente de do bebê no decorrer de todo o trabalho de parto. Esse utiliza-se de técnicas não farmacológicas e não invasivas, proporcionando alívio e conforto durante o trabalho de parto, melhorando o quadro álgico e promovendo relaxamento e tranquilidade à gestante. Dentre essas técnicas destacam-se cinesioterapia, banhos quentes, crioterapia, massagem terapêutica, técnicas respiratórias, caminhada, posturas verticais, exercícios com a bola suíça e TENS.

Qual o papel do fisioterapeuta no atendimento à gestante durante o pré-parto e como é difundido esse serviço? A fisioterapia traz benefícios na assistência à mulher gestante antes do parto? Justifica-se este estudo para demonstrar se a atuação do fisioterapeuta no pré-parto promove benefícios à gestante e ao 
bebê. $O$ presente artigo tem como objetivo abordar sobre o papel do fisioterapeuta na assistência no préparto.

\section{METODOLOGIA}

O presente estudo trata-se de uma revisão bibliográfica onde foi realizada uma pesquisa documental através de busca online em bases SCIELO, Portal de Periódicos da CAPS, LILACS, BIREME e livros do acervo da biblioteca da Faculdade Guaraí, no período de fevereiro de 2018, levantando publicações relativas ao tema nos últimos 8 anos e um livro lançado há 15 anos. Os descritores utilizados foram: 'assistência hospitalar', 'gravidez' e trabalho de parto. Foram encontrados 21 trabalhos, destes selecionados 15 que se inclinam ao tema.

Os critérios definidos para utilização foram: estudos que citavam a atuação do fisioterapeuta no trabalho de parto, a humanização do parto, o papel do fisioterapeuta na diminuição do tempo de trabalho de parto, abordagem fisioterapêutica no pré-parto, em periódicos nacionais, em português, independentemente do método de pesquisa, apresentando texto completo disponível e listados nas bases de dados.

\section{DISCUSSÃO TEÓRICA}

A hora do parto é rodeada por angústia, medo e fantasias, visto que as gestantes não se sentem ou não estão preparadas para o momento do nascimento do filho. Há uma necessidade de que no decorrer do pré-natal hajam estratégias que orientem e informem às gestantes de forma individual ou em grupo a respeito do momento do parto. Essas informações precisam abranger as etapas do trabalho de parto e seus principais sintomas como eliminação do tampão mucossanguinolento, cólicas abdominais decorrentes das contrações uterinas e o rompimento da bolsa de líquido amniótico.

Em benefício à gestante, a presença de um acompanhante ofertando apoio, conforto físico e emocional e outras formas de ajuda é importante. Ela tem o direito de escolher seu acompanhante, e esse precisa ser alguém de sua confiança e convívio. Assim, o acompanhante ajuda a melhorar a qualidade de atendimento da paciente auxiliando no bom andamento do processo de trabalho de parto e parto (VALENCIANO et al., 2015).

A gestante possui um aumento doloroso em situações de estresse, medo, tensão, fadiga, solidão e desamparo social e afetivo, pelo não conhecimento a respeito do processo e também por causa do ambiente estranho, no caso, o hospital. Em contrapartida, o relaxamento, a confiança, o acesso às informações corretas, contato contínuo com familiares, sentir-se ativa, promovem diminuição na percepção da dor. Assim, é possível diminuir esse quadro doloroso e melhorar a qualidade de vida no período pré-parto às gestantes.

Com relação à dor da parturiente os métodos não farmacológicos vêm sendo postos como uma opção que substitui os anestésicos e analgésicos no decorrer do trabalho de parto. Dessa forma, a fisioterapia busca reduzir o período de dilatação como também preparar o períneo para o período expulsivo. 0 
atendimento fisioterapêutico se utiliza dos mais variados métodos não farmacológicos e proporciona essa melhoria e tranquilidade à gestante.

A dor que ocorre no decorrer do trabalho de parto é uma resposta fisiológica, complexa, subjetiva e multidimensional aos estímulos sensoriais gerados, principalmente, pela contração uterina. Segundo Sousa et al. (2014), a dor que a parturiente sente durante o trabalho de parto e parto é influenciada por diversos fatores e é única para cada mulher. Esses fatores incluem ansiedade e medo, experiência anterior de parto, preparação para o parto e suporte oferecido durante este processo.

Portanto, há uma necessidade de assegurar o alívio da dor e da ansiedade à parturiente, pois, estes mecanismos podem ser prejudiciais para o feto afetando a progressão fisiológica do trabalho de parto. Com a utilização de procedimentos não farmacológicos, busca-se alcançar benefícios de redução da dor, favorecendo a colaboração ativa da mulher propiciando uma maior cooperação do acompanhante.

Com o intuito de amenizar esses efeitos e fazer com que o parto seja mais fisiológico e natural, o parto vaginal vem sendo cada vez mais empregado, podendo se destacar o parto humanizado, que tem como objetivo a utilização da liberdade corporal, e não os métodos farmacológicos que podem trazer muitas complicações a curto, médio e longo prazo, à mãe e a criança durante o processo do parto.

O parto humanizado visa respeitar a individualidade da parturiente, escutar suas necessidades e adequar a assistência segundo a cultura, às crenças e os valores das mulheres. No Brasil, o Ministério da Saúde, desde o ano 2000, vem buscando resgatar a participação mais ativa da gestante durante o processo do parto, incentivando as maternidades a aderirem no programa de parto humanizado visando garantir que a parturiente tenha maior consciência corporal, para então poder fazer com que seu corpo se torne um instrumento fundamental no processo de parto.

Assim, como o fisioterapeuta compreende todos os movimentos do corpo humano, ele é um dos profissionais habilitados a colaborar no atendimento à parturiente, estando apto a utilizar técnicas não farmacológicas para o alívio da dor, oferecendo suporte físico e emocional e proporcionando diminuição do medo e da ansiedade. O fisioterapeuta prepara a gestante com orientações, a fim de promover um preparo cardiorrespiratório e físico, para que a mesma tenha um parto tranquilo.

Sousa et al. (2014) ressalta ainda a possibilidade da dor no parto faz com que algumas mulheres optem por uma cirurgia, talvez porque a ênfase cultural da dor do parto natural é maior e mais difundida do que a dor da cesárea. O medo da dor ganha força e legitimidade através da medicalização, pois a cesárea nos é apresentada como segura, inócua e desvinculada da dor.

Sousa et al. (2014) observou que a intervenção fisioterapêutica na assistência ao trabalho de parto auxilia na ação da estrutura osteomuscular facilitando a progressão do trabalho de parto, melhorando a mobilidade pélvica, promovendo a evolução da dilatação, além de que o uso consciente do corpo, estimulado pelo auxílio do fisioterapeuta, favorece o parto vaginal.

De acordo com Sousa et al. (2014), a valorização do trabalho do fisioterapeuta na assistência à gestante em trabalho de parto cada dia aumenta e vem tornando-se de grande importância no alívio da dor durante o parto, aumento da dilatação progressiva do colo uterino, que irá facilitar a saída do bebê, 
orientações quanto à respiração e à força adequada a ser utilizada, e o posicionamento durante o parto propriamente dito.

Os métodos não farmacológicos atuam para reduzir percepção dolorosa da dor no trabalho de parto, sendo métodos ou técnicas consideradas como não invasivos. Dentre eles, pode-se citar: o banho de chuveiro ou de imersão; massagens na região lombar; respiração padronizada; condicionamento verbal; e relaxamento muscular. Esses métodos podem ser aplicados de forma combinada ou isolada, e, além de proporcionar alívio da dor de parto, podem reduzir a necessidade na utilização de métodos farmacológicos

As técnicas fisioterapêuticas que são mais executadas e promovem melhoria nas pacientes são cinesioterapia, banhos quentes, massagens terapêuticas, exercícios respiratórios, caminhada, posturas verticais, exercícios com a bola suíça e neuroeletroestimulação (TENS). Estas técnicas promovem evolução do trabalho de parto e conforto da paciente, no entanto é a paciente quem decide qual técnica é mais confortável, aceitável, relaxante e estimulante para o momento. Sendo assim cada paciente terá um protocolo de atendimento diante de suas aceitações e capacidades de realizar cada exercício. Romano et al. (2013) afirma que:

Durante o atendimento da gestante, o fisioterapeuta deve ter em mente que quanto mais dirigir atenção a esse processo e enfatizar o relaxamento com exercícios que irão facilitar a dilatação, melhor será a evolução e maior será a qualidade de vida proporcionada à parturiente e ao bebê. Na primeira fase do trabalho de parto o fisioterapeuta orienta a parturiente sobre as formas de diminuir as tensões musculares, com posturas que propiciam a dilatação. Já na segunda fase, é de suma importância a participação da parturiente, pois esta fase engloba a expulsão do feto e exigirá da mesma uma postura e respiração adequadas para o nascimento do bebê.

Durante o pré-parto, é essencial o fisioterapeuta assistir a parturiente, procurando manter o corpo móvel e ajudando a coordenar a ação da musculatura e incentivando movimentos funcionais para cada fase da dilatação. Consequentemente, além da redução do número de cesáreas, os exercícios estimulam a diminuição da dor e a duração do trabalho de parto. No entanto, o Brasil tem ainda restrição da atuação do fisioterapeuta no trabalho de parto a poucos centros médicos que incentivam o parto normal, entretanto em países como a Inglaterra e a Alemanha, essa prática vigora há mais de 40 anos.

Na França, toda grávida é orientada a fazer ao menos 12 consultas com o fisioterapeuta no pré-natal (CIRNE, 2009). Com a execução de estratégias não farmacológicas para o alívio da dor, o processo do trabalho de parto poderá ser menos doloroso, menos tenso, devido as mesmas necessitarem de atenção, aconselhamento e habilidades de comunicação.

\section{Técnicas utilizadas pelo fisioterapeuta na assistência à gestante: cinesioterapia}

A cinesioterapia engloba exercícios realizados em músculos estressados, hipotônicos, atrofiados, melhorando a capacidade funcional, motora, biomecânica, cinesiológica e proprioceptiva ajudando a diminuir a compensação, o quadro álgico, os desconfortos, favorecendo o ganho de ADM (amplitude de movimento). É uma técnica bastante utilizada em gestantes favorecendo melhora das dores, melhorando os movimentos do corpo (VIEIRA et al., 2017). 
No pré-parto, a cinesioterapia tem como objetivo aliviar quadro álgico, capacitar o assoalho pélvico para sustentação do útero, prevenir patologias, favorecer relaxamento e cooperar com a dilatação do colo uterino para a hora do parto. O fisioterapeuta atua buscando melhorar a força da parturiente para o momento do parto, as condições posturais, as estruturas e a sustentação do corpo. Proporciona melhoria na postura da coluna vertebral viabilizando adaptações biomecânicas e buscando o controle do estresse muscular e das dores em regiões lombares e pélvica.

Vieira et al. (2017) relata que os exercícios posturais utilizados no período intraparto podem ser alongamento de forma cautelosa de extensores cervicais, músculos da escápula, extensores da coluna lombar, adutores do quadril, isquiotibiais e flexores da região plantar. Exercícios de fortalecimento também podem ser realizados e também de forma ponderada e baixa intensidade de flexores cervicais e torácicos, músculos da retração da escápula, rotadores externos do ombro, extensores do quadril, extensores do joelho e dorsiflexores do tornozelo.

A cinesioterapia pode ser realizada através de exercícios com bola e bastão, exercícios de retroversão e anteversão pélvica, exercícios ativos de membros superiores e inferiores, deambulação associada a exercícios de membros superiores e respiratórios. Sendo que é necessário respeitar a aceitação e capacidade de cada mulher.

\section{Banhos quentes}

No decurso do trabalho de parto, a água morna restringe a sensibilidade dolorosa da parturiente através da redução da atividade simpática, pois modifica a transmissão aferente nociceptiva tornando-a mais lenta e elevando os níveis de encefalinas e endorfinas endógenas. Utilizando o chuveiro com a água caindo sobre as costas da gestante ocorre o alívio da dor lombar, que é uma queixa frequente que pode ser devido a apresentação posterior da cabeça do feto, no primeiro estágio do parto (BAVRESCO et al., 2011).

A termoterapia é utilizada para diminuir a dor no parto, uma vez que promove relaxamento geral nas parturientes, sem gerar efeitos indesejados sobre o perfil biofísico do feto. Geralmente empregada através de banho quente com o chuveiro, deixando a água cair sobre a costa da gestante, propiciando alívio da dor lombar, queixa que acomete parturientes em estágio de parto.

O banho quente ou 'banho de imersão' é uma alternativa para o conforto da parturiente, aliviando a dor sem interferir na progressão do trabalho de parto. A água aquecida induz à vasodilatação periférica e favorece a redistribuição do fluxo sanguíneo, proporcionando o relaxamento muscular. Sendo assim, uma técnica muito utilizada para promover alívio da dor durante o trabalho de parto.

O banho quente é uma opção viável para promover o conforto da parturiente no primeiro período do trabalho de parto, além de possibilitar melhores condições de colaboração ativa da parturiente e outorgando maior participação do acompanhante. O uso dessa técnica pode ser associado à utilização da bola e à massagem lombar melhorando o resultado que se espera alcançar. 


\section{Massagem terapêutica}

A massagem é um recurso aplicado através de estimulação sensorial pelo toque sistêmico e pela manipulação dos tecidos da pele. Durante o trabalho de parto, promove alívio da dor e também um contato físico com a paciente intensificando o efeito de relaxamento e diminuição do estresse emocional, melhorando o fluxo sanguíneo e a oxigenação dos tecidos. A massagem pode ser realizada com técnicas de deslizamentos superficiais e suaves, com aplicação de cremes ou óleos, na gestante sentada ou deitada em decúbito lateral esquerdo.

Existem várias formas de massagear a parturiente sendo: massagem do tecido conjuntivo nas zonas reflexas do baixo ventre e região sacral; massagem leve e suave com as mãos abertas de um lado ao outro da região de baixo ventre; massagem através de batidas leves com os dedos no baixo ventre de um lado para o outro; deslizamento na região sacrococcígea até as cristas ilíacas; massagem profunda sobre a região sacral; massagem com as duas mãos sobre as articulações sacrilíacas, no sentido longitudinal do occipital até o cóccix, em paralelo à coluna vertebral (BAVARESCO et al., 2011). Silva et al. (2015) afirma que:

As massagens são aplicadas principalmente na região lombo sacra e nas pernas, que são os locais onde as gestantes mais referem quadro álgico. A massagem na região perineal também é muito indicada, principalmente para gestantes que expressam maiores riscos de lacerações, como as que estão realizando o primeiro parto vaginal. Com o relaxamento das fibras, a tensão local é aliviada, prevenindo assim, maiores lacerações na hora do parto e evitando a episiotomia.

A massagem pode ser realizada em todo o corpo da paciente desde que esta sinta-se confortável em receber esta forma de intervenção, afirmando que a parturiente tem benefícios de alívio da dor e ansiedade conduzindo de maneira eficiente o trabalho de parto. A massoterapia reduz ansiedade, estresse, fadiga muscular, promove relaxamento, possui ação sedativa e analgésica, aumenta a consciência corporal beneficiando o sistema emocional e equilibrando o sistema simpático e parassimpático

\section{Exercícios respiratórios}

A respiração é imprescindível durante o trabalho de parto e parto. Age promovendo relaxamento, obtendo concentração, diminui os riscos de trauma perineal no momento expulsivo, e melhorando a oxigenação sanguínea da mãe e do feto. Não existe um protocolo ideal a ser seguido durante o trabalho de parto. O fisioterapeuta precisa estimular o uso correto da musculatura respiratória através de respiração espontânea, diafragmática, natural e leve, conscientizando a mulher para a hora do parto manter a respiração adequada beneficiando a oxigenação própria e do bebê (BAVARESCO et al., 2011).

As técnicas respiratórias utilizadas no trabalho de parto são respiração torácica e respiração abdominal, sendo a torácica empregada no momento das contrações por promover maior expansão torácica, aliviando o fundo uterino e favorecendo maior oxigenação. Por outro lado, a respiração abdominal é indicada nos intervalos das contrações, visto que proporcionam o relaxamento. Os exercícios respiratórios quando realizados corretamente resultam em tranquilidade e relaxamento, entretanto não há uma técnica específica a ser seguida. O fisioterapeuta precisa orientar a gestante a utilizar corretamente a musculatura respiratória para ofertar uma qualidade de oxigenação para mãe e bebê (SILVA et al., 2015). 
Os exercícios respiratórios possuem a função de reduzir a sensação dolorosa, melhorar níveis de saturação de oxigênio, proporcionar relaxamento e diminuir ansiedade. No entanto, os exercícios respiratórios realizados sem associação de outros métodos, podem não ser suficientes para reduzir a sensação dolorosa no primeiro estágio do trabalho de parto, porém são eficazes para diminuir a ansiedade.

\section{Estímulo à deambulação e posturas verticais}

As posturas verticais e a mobilidade materna durante o trabalho de parto são práticas consideradas vantajosas e seguras para a parturiente. A mobilidade materna e a liberdade de movimento simplificam o processo de encaixe do bebê à pelve materna e ao canal de parto., sendo que a mobilidade pélvica é diferente nas várias posturas que podem ser adotadas no pré-parto. As posturas que também podem ser adotadas com auxílio do fisioterapeuta incluem ajoelhada, sentada, quatro apoios, sentada em cadeiras especiais, inclinada para a frente com apoio em uma parede. Estas posturas promovem relaxamento em especial da musculatura dorsal, do assoalho pélvico e do canal vaginal.

A deambulação em conjunto com as posturas verticais diminui a duração do trabalho de parto, aumentam a tolerância à dor minimizando a utilização de fármacos e contribuindo para a evolução da dilatação. Porém, é preciso ser realizado adjunto à deambulação outras estratégias, como mobilidade da parturiente e posicionamento vertical. A postura de decúbito lateral esquerdo melhora a oxigenação fetal e evita a hipotensão supinada. O decúbito dorsal por tempo prolongado diminui o ritmo das contrações e alivia a dor. No entanto, é preciso respeitar a posição que a gestante se sentir mais confortável.

\section{Exercícios com bola suíça}

Postura vertical e movimentação proporcionam minimização da dor materna, facilitando a circulação materno-fetal e a descida do feto na pelve materna, melhora nas contrações uterinas e diminuição do trauma perineal, motivo pelo qual a influência das mudanças de posição materna no parto vem sendo utilizadas com resultados satisfatórios. A bola suíça é uma das estratégias para a promoção da livre movimentação da mulher durante o parto. É um recurso que estimula a posição vertical, permite liberdade na adoção de diferentes posições, possibilita o exercício do balanço pélvico por sua característica de objeto lúdico, que traz benefícios psicológicos, além de ter baixo custo financeiro (SILVA et al., 2011).

Entre os principais benefícios trazidos por exercícios com a bola na gravidez e no trabalho de parto, estão a correção da postura, o relaxamento e alongamento e o fortalecimento da musculatura. A realização de exercícios com a bola na posição vertical trabalha a musculatura do assoalho pélvico, em especial, os músculos levantadores do ânus e pubococcígeos e a fáscia da pelve. Essa posição proporciona liberdade de mudança de posição à parturiente, o que contribui para a participação ativa da mulher no processo do nascimento. A movimentação suave da pelve promove o relaxamento da musculatura, que associada à ampliação da pelve auxilia na descida da apresentação fetal no canal de parto (SILVA et al., 2011).

Corroborando com esse estudo Oliveira et al. (2014) disserta que são inúmeros os benefícios trazidos pelo uso da bola no trabalho de parto, citando a correção da postura, o relaxamento, o alongamento e o 
fortalecimento da musculatura. Além disso, os exercícios na bola com a paciente sentada trabalham a musculatura do assoalho pélvico, principalmente os músculos levantadores do ânus e pubococcígeo, além da fáscia da pele, o que causa ampliação da pelve auxiliando na descida da apresentação fetal no canal de parto além de trazer benefícios psicológicos e ter baixo custo financeiro.

A bola obstétrica é considerada um instrumento lúdico que distrai a parturiente, tornando o trabalho de parto mais tranquilo e que serve de suporte para outras técnicas, como por exemplo, a massagem e o banho de chuveiro, como também para a realização de alongamentos e exercícios ativos de circundução, anteversão e retroversão pélvica, constituindo-se como um dos métodos não farmacológicos de alívio da dor no trabalho de parto. Está classificada, juntamente com outras recomendações da OMS, na categoria de condutas que são claramente úteis e que deveriam ser encorajadas no trabalho de parto e parto.

\section{Neuroeletroestimulação Nervosa Transcutânea (TENS)}

A TENS é uma medida não farmacológica bastante difundida, segura, não invasiva, de fácil aplicação, remoção e baixo custo. Envia impulsos elétricos através de eletrodos posicionados na região para vertebral no nível de T10 e L1, correspondente à inervação uterina e do cérvix e na região ao nível de S2 e S4, correspondente à inervação do canal de parto e assoalho pélvico. Tem como efeito a analgesia, os impulsos elétricos inibem as transmissões dos impulsos dolorosos através da medula espinhal fazendo com que o organismo libere opioides endógenos como a endorfina através das sinapses do sistema nervoso centra proporcionando assim o alívio da sensação dolorosa (VALENCIANO et al., 2015).

A corrente TENS é utilizada em gestantes no primeiro estágio do trabalho de parto, objetivando diminuir a sensação dolorosa, retardar a utilização de fármacos minimizando o tempo de exposição da mãe e do feto aos métodos farmacológicos e a incidência de seus efeitos nocivos. É uma forma eficaz alcançando o objetivo sendo ideal utilizar juntamente com outros recursos, sendo que este mecanismo promove apenas analgesia.

O uso da TENS como forma de analgesia para o parto está bastante difundido por ser um método considerado seguro, não invasivo e sem drogas farmacológicas, proporcionando um parto relativamente sem dor. Não há uma unanimidade na literatura que afirme qual parâmetro seja mais adequado, no entanto, são frequentemente empregadas altas frequências de 80 a 100Hz, menor duração de pulso de 75 a $100 \mu$ s e intensidade conforme a sensibilidade da parturiente. Os eletrodos são posicionados na região lombo sacra, onde ocorre maior quadro álgico. A TENS proporciona uma analgesia local, dando um conforto maior à parturiente. Teoricamente, a TENS influenciaria na função cardíaca fetal, contudo, não existem evidências científicas em relação a essa possibilidade.

Bavaresco et al. (2011), através de seu estudo, referem que existem fracas evidências cientificas para o uso contínuo da TENS como intervenção na dor obstétrica, no entanto não é coerente descartar seu uso, pois seu emprego possui resultados animadores. E também a TENS para alívio da dor no parto já foi submetida a estudos controlados mais que quaisquer outros métodos analgésicos não farmacológicos, 
porém com resultados ainda não conclusivos. No entanto não se pode negar sua eficiência e segurança através de concordância entre as pesquisas realizadas.

\section{CONCLUSÕES}

A atuação do fisioterapeuta na atenção à gestante no pré-parto é de extrema importância, constatando-se através do estudo realizado que este é habilitado a realizar um atendimento qualificado, contribuindo de forma positiva na boa evolução do trabalho de parto e parto, mostrando que na área obstétrica é imprescindível a presença do fisioterapeuta, e que seus benefícios são muito satisfatórios proporcionando às gestantes redução da percepção dolorosa, do medo e da ansiedade, aumentando a confiança, o bem-estar e maior compreensão sobre o processo de trabalho de parto e parto.

No entanto percebe-se que este serviço, ou seja, a presença do fisioterapeuta no pré-parto não está bem difundida, constatando-se que poucos centros ou hospitais oferecem esta modalidade de atendimento. No Brasil este serviço ocorre apenas em poucos centros médicos que incentivam o parto normal. Percebe-se que é necessário propagar estas estratégias de assistência melhorando a qualidade de tratamento da gestante e do feto.

Desta forma é recomendável que a fisioterapia obstétrica seja mais reconhecida e analisada por graduados e graduandos da área, visto que sua eficiência é comprovada. Constata-se que a paciente precisa conhecer melhor a importância da atuação do fisioterapeuta no processo de parto. Fica evidenciado ainda que os recursos utilizados, além de seguros, contribuem para um parto mais efetivo e humanizado, beneficiando assim a gestante e ao recém-nascido.

\section{REFERÊNCIAS}

ABREU, N. S.; CRUZ, M. V.; GUERRA, Z. F.; PORTO, F. R.. Atenção Fisioterapêutica no Trabalho de Parto e Parto. Revista Interdisciplinar de Estudos Experimentais, Juiz de Fora, v.5, p.7-15, 2013.

BARROS, A. P.; MATOS, S. S.. A Importância da Atuação do Fisioterapeuta no Parto Vaginal em Primigestas e Multíparas. Revista Científica Multidisciplinar Núcleo do Conhecimento, Porto Velho, v.1, n.6, p.282-291, 2017.

BAVARESCO, G. Z.; SOUZA, R. S. O.; ALMEIDA, B.; SABATINO, J. H.; DIAS, M.. O Fisioterapeuta como Profissional de Suporte à Parturiente. Ciência \& Saúde Coletiva, Florianópolis, v.16, n.7, p.3259-3266, 2011.

CASTRO, A. S.; CASTRO, A. C.; MENDONÇA, A. C.. Abordagem Fisioterapêutica no Pré-Parto: proposta de protocolo e avaliação da dor. Fisioterapia e Pesquisa, Uberaba, v.19, n.3, p.210-214, 2012.

CIRNE, S. L.. Humanizar para Saúde Gestacional: Papel do Fisioterapeuta. Monografia (Graduação em Fisioterapia) Universidade Veiga de Almeida, Rio de Janeiro, 2009.

DAVIM, R. M. B.; TORRES, G. V.; DANTAS, J. C.; MELO, E. S.; PAIVA, C. P.; VIEIRA, D.; COSTA, I. K. F.. Banho de Chuveiro como Estratégia não Farmacológica no Alívio da Dor de
Parturientes. Revista Eletrônica Enfermagem, Natal, v.10, n.3, p.600-609, 2008.

LUIS, L. A.; SANTOS, P. C. O.; MATCUMOTO, T. A. S.; AQUINO, S. R. J.. Intervenção Fisioterapêutica no Preparo e Durante o Parto. Monografia (Graduação em Fisioterapia) Faculdades Integradas de Fernandópolis, Fernandópolis, 2017.

OLIVEIRA, L. M. N.; CRUZ, A. G. C.. A Utilização da Bola Suíça na Promoção do Parto Humanizado. Revista Brasileira de Ciências da Saúde, Teresina, v.18, n.2, p.175-180, 2014.

ROMANO, F. B.; VELASCO, A. F.; JÚNIOR, H. J. S.; OLIVEIRA, S. G.. Protocolo Fisioterapêutico no Trabalho de Parto no Hospital Materno Infantil Nossa Senhora de Nazareth em Boa Vista (RR). Caderno de Ciências Biológicas e da Saúde, v.4, n.1, Boa Vista, 2013.

SILVA, C. F.; LUZES, R.. Contribuição da Fisioterapia no Parto Humanizado: Revisão de Literatura. Revista Discente da UNIABEU, v.3, n.6, p.25-32, Rio de Janeiro, 2015.

SILVA, L. M.; OLIVEIRA, S. M. J. V.; SILVA, F. M. B.; ALVARENGA, M. B.. Uso da Bola Suíça no Trabalho de Parto. Acta Paulista de Enfermagem, v.24, n.5, p.556-562, São Paulo, 2011. 
SOUSA, D. P. F.; CUNHA, F. M. A. M.. A Fisioterapia na Preparação para o Trabalho de Parto: uma Revisão Integrativa. Revista Digital Buenos Aires, Sobral, v.19, n.195, 2014.

STEPHENSON, R. G.; O'CONNOR, L. J.. Fisioterapia Aplicada à Ginecologia e Obstetrícia. 2 ed. Barueri: Manole, 2004.
VALENCIANO, C. M. V. S.; RODRIGUES, M. F.. A importância da intervenção fisioterapêutica na assistência do trabalho de parto. Monografia (Graduação em Fisioterapia) - Centro Universitário Católico Salesiano Auxilium, Lins, 2015.

VIEIRA, A. F. M.; SILVA, P. D. S.; JUNIOR, P. R. B.; MATHIAS, C. M. F.. Os benefícios da cinesioterapia no pré e pós-parto normal. Revista Conexão Eletrônica, v.14, n.1, p.1924-1932, Três Lagoas, 2017.

A CBPC - Companhia Brasileira de Produção Científica (CNPJ: 11.221.422/0001-03) detém os direitos materiais desta publicação. Os direitos referem-se à publicação do trabalho em qualquer parte do mundo, incluindo os direitos às renovações, expansões e disseminações da contribuição, bem como outros direitos subsidiários. Todos os trabalhos publicados eletronicamente poderão posteriormente ser publicados em coletâneas impressas sob coordenação da Sustenere Publishing, da Companhia Brasileira de Produção Científica e seus parceiros autorizados. Os (as) autores (as) preservam os direitos autorais, mas não têm permissão para a publicação da contribuição em outro meio, impresso ou digital, em português ou em tradução. 